\title{
Alfabetização Científica e a Contextualização do conhecimento: um estudo da Física aplicada ao trânsito
}

Scientific Literacy and knowledge contextualization: a study of traffic applied Physics

\author{
Patrick Alves Vizzotto*10, Luiz Fernando Mackedanz²0
}

${ }^{1}$ Universidade do Vale do Taquari, Programa de Pós-graduação em Ensino, Lajeado, RS, Brasil

${ }^{2}$ Universidade Federal do Rio Grande, Instituto de Matemática, Estatística e Física, Rio Grande, RS, Brasil

Recebido em 5 de Fevereiro de 2019. Revisado em 16 de Abril de 2019. Aceito em 31 de Julho de 2019

\begin{abstract}
Apresentamos os resultados de um estudo com egressos do Ensino Médio que buscou investigar o nível de alfabetização científica e a capacidade de interpretar situações do trânsito à luz da Física. A partir desta mensuração, realizamos testes estatísticos a fim de inferir se tais índices possuíam conexão com as aulas de Física que os participantes vivenciaram e também com o grau de informação sobre temas científicos que acreditavam deter. Como resultados, foi possível evidenciar ligações estatisticamente significativas entre a maioria dos constructos analisados, destacando a correlação entre o nível de alfabetização científica de quem assistiu aulas de Física com características que poderiam potencializar uma Aprendizagem Significativa. Como contribuição, defendemos a inclusão de um quarto eixo, o da proficiência científica, no modo de mensurar o nível de alfabetização científica, postulado por Jon Miller, no qual considera alfabetizado cientificamente aqueles que apresentarem domínio mínimo: 1) dos conteúdos da Ciência; 2) da Natureza da Ciência; e 3) do Impacto da Ciência e Tecnologia na Sociedade e meio ambiente.
\end{abstract}

Palavras-chave: Física aplicada ao trânsito, Mensuração, Proficiência Científica.

We present the results of a study with High School graduates that sought to investigate the scientific literacy level and the ability to interpret traffic situations in the light of Physics. From this measurement, we performed statistical tests in order to infer if these indexes had a connection with previous Physics classes experienced by the participants and also with the degree of information about scientific topics that they believed to hold. As results, it was possible to show statistically significant connections between the majority of the analyzed constructs, highlighting the correlation between the scientific literacy level of those who attended Physics classes with characteristics that could enhance Significant Learning. As a contribution, we defend the inclusion of a fourth axis, Scientific Proficiency, in the way of measuring the level of scientific literacy, postulated by Joh Miller, in which it is considered scientifically literate those who submit minimum domain: 1) of the contents of science; 2) of nature of science; and 3) of the impact of science and technology on society and the environment.

Keywords: Traffic applied Physics, Measurement, Scientific Proficiency.

\section{Introdução}

Qual é o nível de Alfabetização Científica da população? Como mensurar um constructo de significado tão relativo na literatura? Quantos indivíduos possuem a competência de utilizar seus saberes para compreender com maior precisão seus cotidianos? Quais fatores podem influenciar essa aptidão? Tais indagações apresentam questionamentos comumente observados em manuscritos da área [1][2][3], os quais, agregam esforços em prol da pesquisa em Educação em Ciências e do ideário da formação de egressos do sistema escolar cientificamente alfabetizados. A pesquisa apresentada neste manuscrito pretende entrar em ressonância com essas aspirações.

A disciplina de Física busca estudar fenômenos que habitualmente podem ser apreciados no cotidiano. Para

*Endereço de correspondência: patrick.fisica@hotmail.com este estudo, o contexto designado foi o trânsito, pois uma aproximação da Física a situações aplicadas no trânsito pode possibilitar ao estudante melhores compreensões dos conceitos abordados em sala de aula [4]. Praticamente todos nós estamos permeados por esse contexto e assim, se constitui de uma fonte rica de exemplos nos quais a Física pode ser utilizada para contextualizar os assuntos abordados dentro do Ensino Médio.

Além da pertinência apresentada, há também razões de cunho social que amparam a relevância da união entre a Física e o trânsito, pois entre os agravantes de maior ocorrência nas mortes de trânsito, estão os concernentes a negligências e imprudências derivadas, ambas, da tomada de decisão dos condutores e pedestres [5].

À vista disso, é presumível, embora não seja causal, que seja de maior probabilidade que, aquele cidadão detentor de percepções de maior noção quanto ao vínculo de causa 
e efeito das suas ações, tome decisões com maior grau de criticidade em seu cotidiano.

De acordo com Miller [6], para um cidadão ser considerado como alfabetizado cientificamente deve apresentar, após o término da Educação Básica, níveis mínimos de entendimento em três eixos: conteúdos da ciência; natureza da ciência; e impacto da ciência e tecnologia na sociedade. Fazendo uso dessa base teórica e acrescentando os objetivos da educação científica postulados pela American Association for the Advancement of Science [7], Laugksch e Spargo [8] elaboraram um instrumento que visou mensurar quantitativamente os níveis de entendimento supracitados.

Tendo como suporte a linha de investigação desses dois autores, esse estudo apresenta os resultados de uma pesquisa que visou inferir se egressos do Ensino Médio possuem a competência de utilizar os seus saberes para julgar a coerência científica de situações físicas aplicadas ao cotidiano do trânsito e assim, notar se tal qualificação possui vínculo estatístico com o nível de Alfabetização Científica (doravante citada como "AC"), interesse por temas científicos e com as aulas de Física que os mesmos vivenciaram enquanto estudantes da Educação Básica.

Os participantes foram egressos do Ensino Médio, ingressantes de cursos técnicos, tecnólogos e graduação de um Instituto Federal e Universidade Federal do estado do Rio Grande do Sul. Esses, responderam quatro questionários, que visaram mensurar os constructos descritos no parágrafo anterior. Posteriormente, fazendo uso de técnicas estatísticas, analisamos os índices de desempenho e os cruzamos com dados de caracterização dos participantes na busca de correlações significativas [9] [10].

Sustentamos que esse estudo poderá contribuir com a reflexão sobre a retenção de conhecimentos à longo prazo, pois a perspectiva de investigar egressos do Ensino Médio aparece de maneira sutil na literatura nacional, assim como, cooperar com os esforços por uma metodologia quantitativa de mensuração da AC dentro do contexto escolar.

\section{A Alfabetização Científica e o desafio de mensurá-la}

O contexto sócio-político de surgimento do conceito da AC se deu na metade do século XX, mais especificamente, quando no início da corrida espacial-armamentista, a União Soviética lançou o Sputnik 1, em 1957. A detenção dessa capacidade poderia sinalizar, entre outras coisas, maior possibilidade de obter êxito em investidas militares e também desenvolvimento de tecnologias industriais e bélicas contra o principal opositor, os Estados Unidos da América - EUA. Esse feito fez surgir nos EUA um movimento de incentivo a compreender o nível de entendimento científico dos seus habitantes, bem como, suscitar o interesse da população por carreiras correlatas com essa área de conhecimento, como Ciências, Tecnologia, Engenharia e Matemática [2].
Tais incentivos dependiam do investimento de recursos financeiros para sua implementação, pois, além de aplicar dinheiro na pesquisa científica de base, acreditavam que o surgimento de uma cultura científica pressupõe que os estímulos sejam realizados desde os primeiros anos de educação básica de um indivíduo. Tendo em vista esse desafio, o ideário da educação científica recebeu bilhões de dólares de investimento, direcionados para produção de material de instrução, formação de professores, disseminação e transposição do conhecimento científico para o público leigo, além publicações e programas de incentivo à popularização da ciência [11].

A importância de que os conhecimentos científicos estivessem presentes nas ações da população já era defendida anos antes da implementação dos incentivos supracitados. Denominado Atitude Científica, esse conceito foi abordado por autores como Noll [12], Davis [13] e Hoff [14], e seus trabalhos discutiam atributos relevantes que as aulas de disciplinas científicas deveriam apresentar, bem como, as competências que egressos da educação básica deveriam possuir. Ao unir tais objetivos com as necessidades derivadas do momento sócio-político estadunidense, surgiu o ideário que, com o passar dos anos, foi se constituindo no que atualmente denomina-se de Alfabetização Científica.

Esse termo, dentro do contexto educacional, foi postulado por Paul Hurd [15]. Do seu surgimento até a atualidade, esse vocábulo foi objeto de expressiva discussão sobre seu significado, fazendo com que hoje, exista uma diversidade de concepções acerca da sua interpretação.

Para Shen [16], a AC engloba três subdivisões: AC Prática, AC Cívica e AC Cultural. A AC Prática, está conectada ao cotidiano, pois contribui na utilização dos conhecimentos científicos para interpretar e solucionar problemas e melhorar a qualidade de vida da população. A AC Cívica está relacionada à competência de utilizar os saberes científicos para compreender a influência da ciência em ações políticas, potencializando com que a tomada de decisão dentro dessa área possa ser pautada por estes entendimentos. Por sua vez, a AC Cultural é entendida como aquela que está presente no interesse de pessoas sem formação científica, mas que buscam apropriar-se de tais conhecimentos por meio de publicações, cursos, debates, etc., fomentando o cultivo de uma cultura entre indivíduos que partilham desses interesses.

Na visão de Miller [6], a AC também poderia ser subdividida em três eixos estruturantes: Entendimento dos conteúdos da ciência (Eixo 1), Entendimento da natureza da ciência (Eixo 2) e Entendimento do impacto da ciência e tecnologia na sociedade e ambiente (Eixo 3). O eixo 1 refere-se às nomenclaturas, conceitos e também à dimensão histórica da ciência. Por sua vez, o eixo 2 aborda os aspectos epistemológicos e metodológicos da construção do conhecimento científico. Por fim, o eixo 3 tange pontos que versam sobre o domínio crítico necessário para compreender as influências das tecnologias e dos feitos científicos na natureza e sociedade. 
Uma concepção tridimensional também pode ser observada na produção de Bybee [17]. O autor considera que a $\mathrm{AC}$ evolui de modo gradativo, e classifica esta transição em: AC funcional, AC conceitual e processual, e AC multidimensional. A primeira, está relacionada ao processo de aquisição. Essa, pode ser de conceitos, termos técnicos, etc., e possibilita ao indivíduo a capacidade de entender que a ciência possui o seu vocábulo próprio, para assim potencializar a identificação de tais termos em meios de instrução e divulgação científica. A AC conceitual e processual, é entendida como um acréscimo à anterior, na qual se atribui significados aos vocabulários já estabelecidos, potencializando a compreensão dos mesmos. Nessa dimensão, ressalta-se a importância da contextualização como ferramenta para alcançar a evolução da AC funcional para a $\mathrm{AC}$ conceitual e processual. O último estágio de AC é o multidimensional. Esse, consiste em uma união dos dois anteriores, aliada a uma visão de mundo que proporcione aplicar os saberes aprendidos em situações cotidianas, assim como, os auxilie no processo de tomar decisões pautadas pelo conhecimento científico.

Uma das produções científicas realizadas pelos EUA foi o "Project 2061 - Science For All Americans - SFAA" [7], que prescreve os objetivos da educação científica, postulando quais seriam as competências que cada egresso do sistema de ensino básico deveria possuir ao concluir essa etapa de instrução. De modo geral, essa publicação considera como alfabetizado cientificamente aquele indivíduo que utiliza o seu conhecimento científico para tomar decisões e entende a natureza e sua diversidade. Esse egresso da escola compreende as limitações e potenciais da ciência, pois essa é uma construção humana e está em constante revisão e evolução.

Percebe-se na concepção de cada um dos referenciais citados, que a AC pode ser abordada sob diversos aspectos, cada um com suas especificidades, porém com pontos em comum entre todas, como por exemplo, a abordagem de que não basta apenas saber conteúdos científicos para ser considerado como alfabetizado cientificamente, pois é fundamental compreender também a dimensão de construção desse saber. Outro ponto relevante é o destaque de que o conhecimento científico consiga ser utilizado para compreender o cotidiano, para assim haver maiores possibilidades de o indivíduo tomar decisões cientificamente coerentes na sociedade.

Transpondo esse tópico para a língua portuguesa, as distinções não são apenas de significado, mas também de variações na nomenclatura. Os três termos mais utilizados na literatura são "Alfabetização Científica", sendo seguido por "Letramento Científico" e também por "Enculturação Científica".

Ao realizar uma busca no primeiro semestre de 2019 na base de indexação do Google Acadêmico, em páginas somente em português, excluindo patentes e citações, foi possível encontrar aproximadamente 117.000 resultados para o descritor "Alfabetização Científica", 41.500 para "Letramento Científico" e 2.510 resultados para "Enculturação Científica".

A diversidade desses descritores advém da tradução e de justificativas linguísticas. Inicialmente, o termo "Scientific Literacy" foi traduzido de forma literal como Letramento Científico. Porém, na língua francesa, sua tradução consiste em "Alphabétisation Scientifique", e por sua vez, na língua espanhola, "Alfabetización Cientifica", sendo assim, ambas as traduções podem ser transpostas para a língua portuguesa como "Alfabetização Científica".

Nessa última, há autores que diferenciam Alfabetização Científica de Letramento Científico, pois, segundo eles, o primeiro faz referência apenas ao processo de conceituação dos termos e da linguagem científica, enquanto que o segundo, considera o impacto da aplicação desse conhecimento dentro da dimensão social do mundo. Ainda há o termo Enculturação Científica, defendido por autores que argumentam que para se obter êxito nos ideais propostos pela $\mathrm{AC}$, é necessário a criação de uma cultura científica [18] [19].

De acordo com Sasseron e Carvalho [3], há pontos de convergência na concepção de autores que estudam esta temática. Seja Alfabetização, Letramento ou Enculturação, percebe-se o ideário de um ensino que "permita aos alunos interagir com uma nova cultura, com uma nova forma de ver o mundo e seus acontecimentos, podendo modificá-los e a si próprio através da prática consciente propiciada por sua interação cerceada de saberes de noções e conhecimentos científicos" (p. 61).

Além de concordar com as autoras, também adotamos as concepções de Auler e Delizoicov [20], que defendem a ideia de que alfabetizar não se resume a um jogo mecânico de juntar e decodificar letras. Além de ler e escrever palavras, alfabetizar possibilita, segundo Lemke [21], uma "leitura de mundo". Nesse sentido, compreendemos que a $\mathrm{AC}$ consiste em um estado que não se resume somente a nomenclaturas e conceitos técnicos da ciência, mas sim, proporciona interpretar o cotidiano com uma visão pautada pelo conhecimento científico. Uma pessoa considerada alfabetizada cientificamente percebe também o processo de elaboração e evolução da ciência, além de o impacto que os feitos científicos podem causar na natureza e na sociedade.

De acordo com Laugksch e Spargo [8], as concepções sobre a definição de $\mathrm{AC}$ de maior proeminência na literatura foram as de Miller [6], resultado da abrangência do seu modelo tridimensional de compreensão da AC. Conforme os autores, acredita-se que o fato de as produções de Miller buscarem mensurar qualitativa e quantitativamente os níveis de $\mathrm{AC}$, colaborou para a relevância do autor na área, motivo pelo qual o utilizaremos como nosso referencial teórico para as discussões apresentadas nesse manuscrito, pois nosso estudo, de certa maneira, está alinhado com esse objetivo de mensuração [22].

Conforme referido, juntamente com as discussões sobre o conceito de AC, evoluiu também as tentativas de mensurar esse constructo. Após o lançamento da Sputnik, e 
a consequente necessidade de os EUA produzir ciência e engajar indivíduos para as carreiras científicas, fez-se necessário, primeiramente, conhecer o nível de conhecimento científico que a sua população possuía, assim como, após os projetos de AC desenvolvidos, era fundamental existir instrumentos que medissem se tais ações e investimentos estavam apresentando efeitos significativos no público-alvo [23].

As primeiras tentativas aconteceram em 1957, tendo como base os estudos de atitudes científicas citados anteriormente, pois esses forneciam características que um egresso da escola teria de apresentar após sua conclusão [2]. Noll [12], defende que tais atitudes deveriam ser mensuradas, preferencialmente, em contextos cotidianos, não se resumindo a maneiras mecânicas, como exemplos laboratoriais.

Shen [16] defende a importância de se elaborar ações de fomento à educação científica, porém julga como imprescindível desenvolver ferramentas para mensurar tais níveis de forma quantitativa. Segundo Laugksch e Spargo [8], entre as décadas de 1960 e 1990, um número expressivo de estudos com esse objetivo foram publicados, tendo como base, mensurar as características de uma pessoa alfabetizada cientificamente, de acordo com as ideias de Shen [16], Miller [6], e Bybee [17].

Um aspecto criticado por Bybee [17] é que a maioria das iniciativas de mensurar a AC abordava esse tema enfatizando aspectos de vocabulário e conceituação, sendo que a aplicação desses conhecimentos em outras situações era um enfoque não abordado de forma satisfatória pelos estudos, até então. Esse fato, corroborou para que o estudo de Miller [6] obtivesse visibilidade, pois esse, além de propor a aplicação de conhecimentos científicos no cotidiano, apresentou maneiras de mensurar estas características de forma quantitativa [24].

Com base na concepção de AC postulada por Miller [6] e nos objetivos da educação científica do SFAA [7], Laugksch e Spargo [8] divulgaram uma pesquisa, na qual, relatava a elaboração e validação de um questionário, chamado de Test of Basic Scientific Literacy - TBSL, que se propunha a medir o nível de AC de egressos da educação básica da África do Sul. Esse questionário se distingue de outros estudos apresentados, pois é composto por questões fechadas, de verdadeiro e falso, aplicadas em situações cotidianas e aborda em um mesmo instrumento, de modo interdisciplinar, as ciências aplicadas dentro dos três eixos estruturantes da AC, de acordo com o referencial seguido pelos autores.

Após a apresentação dos primeiros resultados de pesquisa utilizando este instrumento, outros autores o empregaram para efetuar medidas de $\mathrm{AC}$ em diversos países do mundo, como na África do Sul [8][25]; Austrália [26]; China [27]; Israel [28]; Brasil [29][30][31]; Estados Unidos [32]; Turquia [33].

Contudo, o TBSL possuía algumas limitações. Segundo os elaboradores, a principal delas era a sua extensão. O instrumento é composto por 110 itens, que mesmo sendo itens curtos, e de resposta dicotômica, o tempo para responde-los ultrapassava o período de uma aula escolar. Somando a esse empecilho, de acordo com NascimentoSchulze [30], é possível que a quantidade de 110 questões pudesse afetar a confiabilidade da medida, devido à fadiga dos respondentes.

Assim, conduzimos uma metodologia de redução instrumental, relatada em Vizzotto e Mackedanz [10], na qual, após um teste piloto, fizemos uso de técnicas estatísticas para diminuir a quantidade de itens do TBSL, reduzindoo de 110 para 45 itens, mantendo constante os indicadores de consistência interna, proporção do constructo medido para cada eixo, e também, poder de medida. Esse instrumento reduzido, na língua portuguesa, foi denominado de Teste de Alfabetização Científica Básica Simplificado TACB-S e tem por objetivo viabilizar a sua aplicação em pesquisas acadêmicas e no contexto escolar, adequando um número exequível de itens de acordo com a quantidade de tempo disponível para a sua aplicação.

Conforme referido, havia uma carência por produzir testes de AC que abordassem a aplicação dos saberes do cotidiano. As produções de Miller [6] e de Laugksch e Spargo [8] ocuparam-se dessa perspectiva. Dentro da psicologia cognitiva, a Teoria da Aprendizagem Significativa [34] está alinhada com essa concepção, pois considera que uma das maneiras de verificação de indícios de Aprendizagem Significativa de um conhecimento é observar se o indivíduo consegue o transpor para situações de aplicação diferentes das que ele aprendeu.

Aprender de modo significativo, é um procedimento por meio do qual um novo conhecimento se relaciona, de modo substantivo e não arbitrário, a outro saber relevante, já presente na estrutura cognitiva do indivíduo. Se relacionar de modo não arbitrário, significa que o conhecimento não vai se relacionar com qualquer aspecto da estrutura cognitiva do aprendiz e sim, se relacionará com conceitos logicamente relevantes, chamados de "Subsunçores". Em segunda instância, se relacionar de modo substantivo, demonstra o que é incorporado à estrutura cognitiva: substância do novo conhecimento, das novas ideias, não as palavras precisas usadas para expressá-las. O mesmo conceito ou a mesma proposição podem ser expressos de diferentes maneiras [35]. Ou seja, os novos saberes se conectam com o conhecimento prévio que o indivíduo já possui. Uma aprendizagem significativa ocorre quando essa ligação acontece. A esta conexão, Ausubel chama de "Ancoragem".

Para que esse processo aconteça, de modo essencial, é necessário que duas condições sejam contempladas: 1) O material deve ser potencialmente significativo. Isso é, deve possuir um significado lógico que proporcione as condições para haver um contato adequado entre esse conhecimento e o estudante. 2) O aprendiz deve exprimir uma predisposição para aprender, a qual não se limita a aspectos motivacionais, mas sim, espera-se que o indivíduo possua em sua estrutura cognitiva "ideias-âncora" 
que sejam relevantes, a fim de se relacionar com o material de instrução [36].

Considerando as duas condições básicas com as quais possam acontecer uma aprendizagem significativa, percebese aspectos de aulas, da didática do professor e dos materiais utilizados que estimulem a passividade entre os estudantes podem não ser práticas potencialmente significativas. Ênfase em práticas que estimulem de forma desconexa a memorização, falta de contextualização, falha na proximidade com a realidade do aprendiz, falta de discussões em sala de aula, entre outras, podem não satisfazer ambas as condições essenciais [37].

Um conhecimento aprendido de forma alinhada ao ponto de vista científico e de modo significativo poderá ser relevante na estrutura cognitiva de um indivíduo para o auxiliar na sua interpretação de mundo, assim como é possível que também o ajude na sua tomada de decisões [38]. Daí a relevância de os conhecimentos serem aprendidos significativamente. Dessa maneira, acreditamos que saberes que façam sentido para o aprendiz, que considerem o seu conhecimento prévio e que se relacionem com o seu cotidiano de forma relevante, possam contribuir para o nível de sua AC.

Essa concepção tem por base a defesa de que é possível que conhecimentos aprendidos de maneira significativa possam apresentar maior estabilidade e taxa de retenção na estrutura cognitiva do indivíduo. Tendo em vista essa hipótese, acredita-se que durante situações corriqueiras do cotidiano, em momentos de mobilização de saberes para interpretá-lo e tomar decisões, os conhecimentos escolares possam estar em evidência em sua mente para serem utilizados em seus julgamentos e compreensões da realidade ao seu redor.

Assim, conhecimentos de Física escolar, aprendidos de maneira significativa e presentes por maior tempo na mente de egressos do Ensino Médio, podem contribuir para suas "leituras de mundo" e então, possibilitar a expectativa de que consigam ser transpostos para o entendimento de contextos cotidianos, como no caso de trânsito. Dessa forma, em comparação à conhecimentos aprendidos de maneira desconectada da realidade e com baixa taxa de retenção, pode-se considerar que uma aprendizagem significativa da Física escolar pode contribuir (embora essa relação não seja causal) para a formação de um motorista, passageiro e pedestre com maior possibilidade de atuar nesse meio de maneira crítica e responsável.

De acordo com Moreira [36], a avaliação de uma aprendizagem significativa envolve observar as competências de compreensão, captação de significados e capacidade de transferências do conhecimento a situações não conhecidas ou não rotineiras. Segundo a Teoria da Aprendizagem Significativa, não há como inferir a ocorrência de uma aprendizagem significativa, pois o processo é interno e uma aprendizagem não se consolida em um intervalo pequeno de tempo. No entanto, o que é possível inferir são possíveis indícios de Aprendizagem Significativa, através de medidas indiretas, que instiguem o indivíduo a transpor seus saberes para situações diferentes das que foram utilizadas em seu processo de ensino e aprendizagem. Para o autor [36], de modo prático, essas novas situações devem ser propostas de forma progressiva, pois o aluno não é acostumado a ser confrontado com ocasiões originais de modo repentino.

Sendo assim, parece adequado apresentar ao indivíduo situações cotidianas nas quais certo conhecimento ensinado possa ser utilizado para dar sentido aos fenômenos observados.

Para essa pesquisa, o contexto selecionado foi o do trânsito, pois a maioria das pessoas estão em contato com esse cotidiano, seja na condição de motorista, seja na de passageiro ou pedestre. Assim, estamos permeados por esse ambiente diariamente e por isso, expostos a diversos fenômenos científicos que na maioria das vezes passa despercebido para a maior parte das pessoas.

Tendo em vista a maneira de mensurar a AC, assim como o desejo de que os conceitos científicos sejam ensinados de modo significativo sempre que possível, nossa pesquisa busca observar as correlações desses constructos com a competência dos participantes em fazer uso de seus conhecimentos para interpretar fenômenos físicos aplicados no trânsito. Na próxima seção, é detalhado o procedimento metodológico que possibilitará o alcance desse objetivo.

\section{Metodologia}

\subsection{Instrumentos de pesquisa}

A fim de alcançar os objetivos propostos, nossa pesquisa fez uso de quatro questionários (ver anexos). O primeiro deles é o questionário denominado de Física Aplicada ao Trânsito - FAT (Anexo 1). Elaborado por nós, o FAT é composto por 25 itens, que apresentam situações de Física aplicada ao trânsito, por meio de proposições, algumas incorretas e outras corretas, do ponto de vista científico. Os respondentes são convidados a utilizar os seus conhecimentos para julgar a coerência de cada item, assinalando como "correto" ou "incorreto". Esse instrumento tem por meta submeter os participantes à análise de situações hipotéticas observadas de modo corriqueiro, em que se faz necessário o uso de seus conhecimentos de Física escolar para compreender a ciência de tal situação.

O segundo instrumento de pesquisa, tem por objetivo mapear, com base no relato dos participantes, qual foi o perfil das aulas de Física a que os mesmos assistiram quando alunos do Ensino Médio. Tendo como base a Teoria da Aprendizagem Significativa [34], foi elaborada uma escala Likert, denominada de Perfil do Ensino de Física - PEF, com características de aulas de Física. Essas, poderiam tender a aulas de Física com potencial de proporcionar uma aprendizagem significativa ou de forma antagônica, aulas que poderiam desfavorecer uma aprendizagem significativa. Características como a pre- 
sença ou ausência de debates em sala de aula, a forma na qual a professora ou o professor introduzia os novos conhecimentos, se considerava ou não os conhecimentos prévios dos alunos, os meios de avaliação utilizados, a motivação em assistir às aulas de Física, entre outras, formaram esse instrumento, composto por 20 itens.

Tanto o FAT quanto o PEF, após sua elaboração, passaram por procedimentos estatísticos de validação, a fim de atestar se os itens criados realmente mensuravam o que foi proposto medir [9].

O terceiro questionário utilizado, trata-se do Teste de Alfabetização Científica Básica Simplificado - TACB-S, referido na seção anterior. Esse, possui uma quantidade de 45 itens, que versam sobre os três eixos que compõe a $\mathrm{AC}$ - na visão de Miller [6] - por meio de questões interdisciplinares e relacionadas com temas científicos. Esse instrumento é respondido de maneira dicotômica, com alternativas de verdadeiro e falso, nas quais, é considerado como alfabetizado cientificamente, quem obtém um mínimo de acertos $(60 \%)$ em cada um dos seus três eixos [6]. Tal questionário, originalmente contém 110 itens [8], porém, conforme também discutido na seção anterior, realizamos um estudo de redução para a sua tradução na língua portuguesa, de modo a viabilizar a aplicação em sala de aula. O estudo de redução e validação do instrumento, pode ser consultado em Vizzotto e Mackedanz [10].

Por fim, o último questionário é um dos instrumentos utilizados para caracterização de participantes na pesquisa relatada por Serrao et al. [39], intitulado "Indicador de letramento científico". Esse estudo, submeteu os respondentes a diversos testes de letramento científico e uma das áreas de caracterização dos participantes os fazia distinguir, segundo suas percepções, o grau de informação científica que os mesmos acreditam deter, a fim de verificar o interesse desses por esses temas. O recorte utilizado apresenta onze temas científicos e, dentro de uma escala, os respondentes assinalaram o quanto sabem ou se interessam sobre cada temática. A inclusão do aporte na nossa pesquisa tem por objetivo correlacionar a percepção do grau de informação - PGI dos entrevistados com os escores obtidos nos instrumentos supracitados (Anexo 2).

Esses quatro questionários e os dados de caracterização dos participantes compõem o conjunto de ferramentas utilizadas em nossa pesquisa, a fim de mensurar aspectos da educação científica dos participantes. O objetivo será analisar os dados à luz de técnicas estatísticas, e investigar a possível correlação entre as características medidas e os escores de desempenho.

\subsection{Público-alvo}

Os participantes foram egressos do Ensino Médio, com idades iguais ou superiores a 18 anos, ingressantes de um Instituto Federal e de uma Universidade Federal da região Sul do estado do Rio Grande do Sul. No total, 512 indivíduos participaram da investigação.

\subsection{Aplicação da pesquisa}

A aplicação dos questionários aconteceu no segundo semestre de 2018, nas primeiras aulas do semestre, assegurando que os ingressantes que cursavam disciplinas das ciências exatas tivessem pouco ou nada de contato com instruções de Física dentro das instituições, portando, apenas o conhecimento advindo da escola ou de situações diversas, socializadas em momentos particulares de suas vivências.

A coleta de dados ocorreu da seguinte maneira: Em sala de aula, primeiramente os objetivos da pesquisa foram explicados, salientando o anonimato dos participantes, assim como, a participação de maneira espontânea. Em seguida, foi entregue o termo de consentimento livre e esclarecido junto ao questionário para ser respondido. O tempo de um período escolar foi dedicado para a aplicação, que durou, no máximo 45 minutos, sendo que o tempo médio de atividade foi de 25 minutos.

Posteriormente, os questionários foram corrigidos e as informações de caracterização e desempenho foram tabeladas em uma planilha eletrônica para posterior análise em software estatístico. Utilizamos o Software Statistical Package for the Social Sciences - SPSS®versão 23, para Windows.

\subsection{Análises estatísticas}

Os resultados serão apresentados na próxima seção, primeiramente por meio da estatística descritiva, utilizandose das medidas de tendência central e dispersão. Em um segundo momento, fazendo uso de técnicas da estatística inferencial, apresentaremos hipóteses testadas, que tiveram por objetivo observar se há algum tipo de relação entre cada questionário que o participante respondeu. Os testes inferenciais utilizados foram os Teste de Correlação de Pearson e do Qui-quadrado.

Uma possível correlação é a medida do relacionamento linear entre variáveis [40]. Ela quantifica, primeiramente, a presença de tal correlação, e se houver, quanto é a intensidade dessa associação. Duas variáveis podem estar relacionadas pelo menos de duas maneiras diferentes: 1) de forma positiva: o que significa que quando uma variável apresenta aumento, a outra também aumentará. Por exemplo: hipoteticamente, quanto maior o índice de vacinação para gripe, maior a possibilidade de as pessoas não adoecerem por esta moléstia no inverno. 2) de forma negativa: neste caso, quando se observa aumento em uma variável, se notará diminuição na outra. Por exemplo: supostamente, quanto mais se pratica um instrumento musical, menos erros serão realizados ao tocá-lo.

É importante salientar que uma correlação, mesmo que forte, não implica necessariamente uma relação de causalidade. Nem sempre variáveis que se correlacionam estarão causando efeito mútuo. Portanto, o que se pode 
inferir de uma correlação, caso um teste de causalidade não seja realizado, é que seja passível de causalidade, mas correlação positiva ou negativa, forte ou fraca, não significa de modo automático, uma relação de causa e efeito [41].

Um dos cálculos utilizados em nossos dados foi o do Coeficiente de Correlação de Pearson. Este teste apresenta como resultado um coeficiente, ou seja, um número entre $-1 \mathrm{e}+1$. Um valor +1 indica que as duas variáveis são inteiramente correlacionadas de forma positiva. Por sua vez, um valor de -1, aponta para uma correlação perfeitamente negativa.

Geralmente, os coeficientes apresentarão valores entre -1 e +1 , sendo que, de acordo com Field [40], indicativos positivos ou negativos, entre 0 e 0,3 , representam uma correlação desprezível; entre 0,3 e 0,5, correlação fraca, entre 0,5 e 0,7 , correlação moderada, entre 0,7 e 0,9 , correlação forte, assim como, a partir de 0,9, correlação muito forte.

Caso um coeficiente apresente um valor baixo, isto não necessariamente significa que não há nenhuma relação entre as variáveis, pois estas, podem possuir uma relação não-linear. Assim, sempre é indicado, para apurar se há tais relações, a elaboração de gráfico de dispersão [41].

Porém, ao possuir variáveis não numéricas, ou seja, dados categóricos como informações nominais (sexo, cor dos olhos, etc.) ou ordinais (escolaridade, turno de estudo, entre outras), também se pode proceder a realização de testes de correlação para averiguar a relação entre as variáveis. Porém, para esse caso, sugere-se utilizar o Teste de Qui-quadrado de Pearson. Esse, é interpretado observando o p-valor de significância da saída do software estatístico. Tal valor permite observar a existência de uma associação significativa, se o mesmo for menor que 0,05 .

Tendo em vista a metodologia apresentada, na seção seguinte serão expostos os resultados advindos de nossa coleta de dados. Primeiramente, será realizada uma descrição das características dos participantes. Na sequência, as informações sobre cada questionário serão exibidas e por fim, os resultados dos testes de correlação utilizados.

\section{Resultados}

\subsection{Caracterização dos participantes}

Os egressos do Ensino Médio constituíram no total, 512 participantes. Quanto ao sexo, $252(49,2 \%)$ eram do sexo feminino e $260(50,8 \%)$, do sexo masculino. Do total, 247 pessoas (48,2\%) possuíam Carteira Nacional de Habilitação - CNH. Quanto a idade, esta oscilou entre 18 e 57 anos, sendo que a maioria $(86,3 \%)$ possuía idades entre 18 e 30 anos.

O ano de conclusão do Ensino Médio oscilou entre 1981, o ano mais distante, e 2018, o mais recente. Cerca de $51 \%$ dos participantes haviam finalizado a Educação Básica depois do ano de 2014. Do total de participantes,
$285(55,7 \%)$ eram egressos de escolas públicas estaduais, $121(23,6 \%)$, de escolas públicas federais, $72(14,1 \%)$, de escolas particulares, 18 (3,5\%), de turmas de Educação de Jovens e Adultos - EJA, e por fim, 16 (3,1\%), concluíram o Ensino Médio por meio da prova do Exame Nacional do Ensino Médio - ENEM. A maioria (84,8\%) estudou durante o turno do dia, uma parcela menor (11,5\%) estudou no turno da noite, e uma minoria $(3,7 \%)$ estudou a maior parte do seu Ensino Médio em um sistema de turno integral.

Atualmente, cerca de 55,5\% dos participantes contavam apenas com o Ensino Médio como o seu maior grau de instrução. Em ordem decrescente, 30,1\% possuíam alguma formação técnica, 7,6\%, já contavam com Pósgraduação e apenas $6,8 \%$, continham alguma graduação. Da quantidade integral de participantes, 68,8\% deles nunca precisou conciliar os estudos com alguma forma de trabalho e apenas $7 \%$ necessitou suspender os estudos em algum momento da sua vida escolar. 78,5\% do total, nunca haviam reprovado durante o Ensino Médio, 12,9\% reprovaram uma vez, e 8,6\% deles reprovaram mais de uma vez. Após a conclusão do Ensino Médio, 65,6\% dos entrevistados não haviam mais assistido aulas de Física.

Enfim, 49,6\% tinha como atividade principal apenas estudar, sem nunca ter trabalhado, enquanto $44,9 \%$ conciliava estudos e trabalho, e 5,5\% estava estudando, porém desempregado.

Com esta caracterização, pode-se perceber um públicoalvo de egressos jovens, equilibrado quanto ao sexo e experiência como motoristas de veículos. O histórico escolar revelou um padrão de indivíduos advindos majoritariamente de escolas públicas estaduais, que puderam, em sua maioria, se dedicar apenas aos estudos, com poucas reprovações e baixo índice de evasão escolar.

\subsection{Análise individual dos questionários}

Questionário 1 - Física Aplicada ao Trânsito - FAT

O FAT, apresentou situações do cotidiano do trânsito em que conceitos e fenômenos físicos estavam inseridos. Buscou-se incluir assuntos não somente de mecânica clássica, mas conteúdos abordados em todas as séries do Ensino Médio. A seguir, exibimos a relação dos assuntos inseridos com os seus respectivos itens: Efeito Doppler (item 25); Energia mecânica (itens 7, 12, 17 e 22); Eletricidade estática (itens 13 e 21); Cinemática (itens 9 e 24); Quantidade de movimento (itens 5, 15 e 23); Princípio da Propagação retilínea da Luz (item 18); Termodinâmica (item 14); Atrito (itens 2, 8, 10 e 11); Movimento circular (item 19); Espelhos esféricos (item 6); Primeira Lei de Newton (itens 3, 4 e 20) e Condensação (itens 1 e 16).

A disposição ordenada de cada questão foi definida após o processo de validação das mesmas, em que um dos procedimentos foi determinar o índice de dificuldade de cada item. Com isso, o recomendado é organizá-los de maneira que os de menor dificuldade sejam os primeiros, e posteriormente, sejam dispostos os de maior dificuldade. 
Este padrão percebido durante a validação também foi possível notar na coleta de dados. O Gráfico 1 apresenta o índice de acertos por questão, sendo possível perceber uma tendência decrescente no nível de acertos.

Conforme exposto, podemos perceber que os itens de maior dificuldade foram os 5 últimos, nos quais abordouse, de forma detalhada, assuntos como eletricidade estática (21), Energia cinética (22), Quantidade de movimento (23), Cinemática (24) e Efeito Doppler (25). Por outro lado, as cinco questões consideradas como de menor dificuldade foram as primeiras. Os assuntos expostos em cada uma delas foram: Condensação (1), Atrito (2), Primeira Lei de Newton (3 e 4) e Quantidade de movimento (5).

Na sequência, o Quadro 1 apresenta os resultados das medidas de tendência central e dispersão do software estatístico. Salientamos que, afim de atestar a veracidade dos dados obtidos, apresentaremos os quadros gerados pelo próprio software, o que justifica, nesses casos, a formatação própria e a linguagem no idioma inglês:

Com a análise estatística, podemos notar que a média de acertos foi de aproximadamente 16 questões. Nenhum dos 512 participantes errou todos os 25 itens e apenas 1

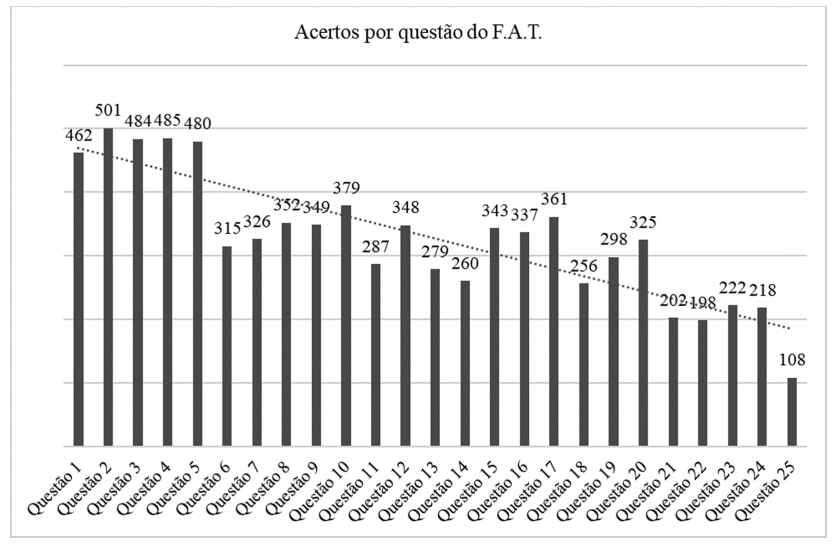

Gráfico 1: Índice de acertos por questão. Fonte: autores.

\begin{tabular}{|c|c|c|}
\hline \multicolumn{3}{|c|}{ Statistics } \\
\hline & & FAT \\
\hline \multirow[t]{2}{*}{$\mathbf{N}$} & Valid & 512 \\
\hline & Missing & $\mathbf{0}$ \\
\hline \multicolumn{2}{|c|}{ Mean } & 15,97 \\
\hline \multicolumn{2}{|c|}{ Median } & 16,00 \\
\hline \multicolumn{2}{|c|}{ Mode } & 16 \\
\hline \multicolumn{2}{|c|}{ Std Deviation } & 3,784 \\
\hline \multicolumn{2}{|c|}{ Minimum } & 6 \\
\hline \multicolumn{2}{|c|}{ Maximum } & 25 \\
\hline
\end{tabular}

Quadro 1: Medidas de tendência central e dispersão para o FAT. Fonte: autores. deles acertou o teste por completo. Para ser considerado com um desempenho aceitável, o participante deveria acertar cerca de $60 \%$ do teste, o que equivale a 15 itens. A percentagem de $60 \%$ atribuída como critério arbitrário de delimitação tem seu fundamento baseado na semelhança de parâmetros das produções envolvendo o TBSL de Laugksch e Spargo [8], nosso referencial de pesquisa, nas quais, também atribuem esse quantitativo como critério. O fundamento para os $60 \%$ considera o desempenho mínimo comumente considerado para aprovação nas instituições de Educação Básica e Superior.

O Quadro 2 apresenta a frequência dos que acertaram 15 ou mais itens:

No entanto, é importante observar que, embora $64,1 \%$ dos 512 participantes tenham obtido êxito em $60 \%$ de acertos, apenas uma parcela correspondente a $3,6 \%$ do total, acertou $90 \%$ ou mais do teste, que corresponde a quantidade de 23 itens.

Sendo assim, apesar de a maioria ter alcançado a média, uma parcela muito pequena obteve um desempenho considerado satisfatório por nós, pois esperava-se que egressos do Ensino Médio, com as características de histórico escolar observadas na seção anterior, pudessem utilizar os seus conhecimentos de Física escolar de maneira mais efetiva nessa atividade.

Questionário 2 - Perfil do Ensino de Física - PEF

O instrumento 2 teve por objetivo mapear, segundo a percepção dos entrevistados, o potencial de suas aulas de Física do Ensino Médio para despertar uma Aprendizagem Significativa. O PEF apresentou, em uma escala Likert, uma série de características das aulas, desde aspectos como a forma de abordagem dos assuntos, organização das salas, presença ou não de momentos de discussão, avaliação, e até mesmo, perspectivas referentes às disposições motivacionais para assistir aulas de Física.

O participante poderia assinalar desde "Concordo plenamente" até "Discordo plenamente", em uma escala de 5 pontos. Cada item poderia então, receber uma pontuação que variou de 1 até 5 pontos. Ao final, esse instrumento gerou um escore individual, que determinou o perfil das aulas de Física. Dessa maneira, quanto maior a pontuação, maior é a tendência de que as aulas proporcionaram um ambiente propício à Aprendizagem Significativa, e de forma contrária, quanto menor o índice, maior a pos-

\begin{tabular}{|l|r|r|r|r|}
\hline \multicolumn{4}{|c|}{ FAT - acerton mais de 15 itens? } \\
\hline & Frequency & Percent & $\begin{array}{c}\text { Cumilative } \\
\text { Percent }\end{array}$ \\
\hline \multirow{2}{*}{ Valid } & Năo & 184 & 35,9 & 35,9 \\
& Sim & 328 & 64,1 & 100,0 \\
& Total & 512 & 100,0 & \\
\hline
\end{tabular}

Quadro 2: Frequência de entrevistados que tiveram desempenho maior que $60 \%$. Fonte: autores. 
siblidade de as aulas não potencializarem tal forma de aprendizagem.

Um número de 20 itens compôs esse instrumento. A seguir, apresentamos os tópicos abordados de forma categórica: Avaliação (itens 1, 9 e 14); Motivação para assistir aulas de Física (itens 2 e 12); Aplicação dos conhecimentos na vida (itens 3, 4, 7, 15 e 18); Aspectos metodológicos (itens 5, 6, 8, 10, 11, 13, 16, 17, 19 e 20).

O questionário PEF completo está no Anexo 3. De forma individual, os itens 7, 9, 18, 19 e 20 foram os que obtiveram maior número de pontuações. Esses cinco itens revelaram que, segundo a percepção dos participantes, características que poderiam potencializar uma Aprendizagem Significativa estavam presentes em seus relatos memorísticos. No entanto, foi possível notar que mesmo assim, aspectos referentes ao formato tradicional de avaliação [42] também eram utilizados pelos docentes.

Os itens menos assinalados foram os de número 3 , 10, 14, 16 e 17. Isso significa que tais características pouco estiveram presentes no cotidiano das aulas de Física dos egressos. O conteúdo presente nessas questões demonstrou que, apesar de haver pouca ênfase na memorização de fórmulas, a avaliação seguia uma tendência de aplicação apenas de provas com resolução de questões; e metodologicamente, não havia a consideração dos conhecimentos prévios dos alunos, nem estímulos para aprofundamento do conhecimento fora do âmbito escolar.

$\mathrm{Na}$ sequência, apresentamos as medidas de tendência central para os escores individuais:

Considerando que utilizamos a escala Likert de 5 pontos, multiplicado pela quantidade de 20 itens, concluímos que a pontuação máxima de um entrevistado poderia atingir os 100 pontos e a pontuação mínima poderia alcançar 20 pontos. No Quadro 3 pode-se notar que a média de pontuação foi de aproximadamente 58 pontos, ultrapassando ligeiramente os $50 \%$ do total.

Para fins de análise, se estabeleceu, de maneira arbitrária, que para considerarmos que as aulas assistidas potencializavam uma Aprendizagem Significativa, as pontuações individuais no PEF também deveriam alcançar

\begin{tabular}{|c|c|c|}
\hline \multicolumn{3}{|c|}{ statistics } \\
\hline & & PEF \\
\hline \multirow[t]{2}{*}{$\mathbf{N}$} & Valid & 512 \\
\hline & Missing & $\mathbf{0}$ \\
\hline \multicolumn{2}{|c|}{ Mean } & 58,41 \\
\hline \multicolumn{2}{|c|}{ Median } & 59,00 \\
\hline \multicolumn{2}{|c|}{ Mode } & 60 \\
\hline \multicolumn{2}{|c|}{ Std Deviation } & 12,498 \\
\hline \multicolumn{2}{|c|}{ Minimim } & 20 \\
\hline \multicolumn{2}{|c|}{ Maximum } & 92 \\
\hline
\end{tabular}

Quadro 3: Medidas de tendência central e dispersão para o PEF. Fonte: autores. o mínimo de $60 \%$ do valor máximo. A seguir o Quadro 4 fornece uma análise dicotômica sobre este panorama.

Com o Quadro 4, notamos que o PEF sinaliza que aulas que não potencializam uma Aprendizagem Significativa tem um escore levemente superior ao das potencializadoras. Isso nos permite observar que os egressos analisados vêm de realidades escolares bastante variadas, desde aulas que faziam alusão ao cotidiano, prezando por discussões e contextualizações, até aulas muito centradas nos métodos de avaliação corriqueiros.

Questionário 3 - Teste de Alfabetização Científica Básica Simplificado - TACB-S

O questionário 3 teve por objetivo mensurar o nível de AC dos participantes, segundo a concepção de Miller [6] e embasados em um instrumento de referência internacional, denominado de TBSL, reduzido por nós [10], de modo a viabilizar sua aplicação no contexto brasileiro, de acordo com o fundamentado na seção de metodologia.

Esse questionário é composto por 45 itens, que versam sobre aspectos científicos de forma básica e interdisciplinar e é apresentado no Anexo 4. O mesmo possui três subdivisões denominadas de eixos: $\mathrm{O}$ eixo 1, contém 27 itens que abordam os conteúdos da ciência, desde sua nomenclatura, significados, até mesmo, aspectos históri$\cos$ (itens $1,2,3,14$ ao 26 , e 35 ao 45); o eixo 2, possui 10 itens sobre a natureza da ciência (itens 4 ao 13), e finalmente, o eixo 3, contém 8 itens sobre o impacto da ciência e tecnologia na sociedade e ambiente (itens 27 ao 34). Assim como nos outros questionários, para ser considerado alfabetizado cientificamente, deve-se obter acertos em pelo menos $60 \%$ de cada um dos três eixos.

De forma semelhante às análises dos outros instrumentos, observamos primeiramente, as questões com menor índice de acertos, sendo elas as de número 2, 5, 10, $30 \mathrm{e}$ 38.

Das 5 questões, nenhuma delas era de domínio da Química ou da Biologia, sendo 2 questões de atribuição da Física. As outras versavam sobre o método científico (eixo 2) e impacto da ciência na sociedade e ambiente (eixo 3). Por outro lado, as questões 11, 40, 41, 44 e 45, apresentaram os maiores índices de acertos.

Verificando de forma individual cada um dos três eixos, pode-se notar que no eixo 1 , apenas $26,4 \%$ dos participantes não obtiveram acerto mínimo de 60\% (17 das 27).

\begin{tabular}{|c|c|c|c|c|}
\hline \multicolumn{5}{|c|}{$\begin{array}{c}\text { As salas poderian potencialine una Aprendingem } \\
\text { Significativa? }\end{array}$} \\
\hline & & Frequency & Valid Percent & $\begin{array}{l}\text { Cumulativ } \\
\text { e Percent }\end{array}$ \\
\hline \multirow[t]{3}{*}{ Valid } & Năo & 258 & 50,4 & 50,4 \\
\hline & Sim & 254 & 49,6 & 100,0 \\
\hline & Total & 512 & 100,0 & \\
\hline
\end{tabular}

Quadro 4: Frequência de entrevistados cujas aulas que poderiam potencializar uma Aprendizagem Significativa. Fonte: autores. 
No eixo 2, 32,4\% dos respondentes não obteve o mínimo de 6 acertos, do total de 10 itens. Por fim, no eixo 3, 40,4\% não acertou 5 das 8 questões. Sobre estes dados, constatou-se que o eixo 1 obteve maior índice de acertos. Esse, sendo um eixo com itens conteudistas, pode fornecer subsídios para a defesa de que aspectos epistemológicos (eixo 2) e de Ciência, Tecnologia e Sociedade - CTS (eixo 3) foram menos contemplados na educação científica dos entrevistados.

De acordo com a orientação dos autores do TBSL [8], mesmo que um indivíduo tenha obtido bons desempenhos em dois dos três eixos do teste, este déficit no eixo restante deve classificá-lo como não alfabetizado cientificamente. Portanto, realizando uma análise integral dos 3 eixos do TACB-S, apenas 169 (33\%) dos participantes puderam ser considerados com um nível de AC aceitável.

Questionário 4 - Percepção Geral de Informação - PGI Finalmente, o questionário 4, criado por Serrao et al. [39], teve por objetivo caracterizar o nível de informação dos indivíduos para assuntos científicos. Esse instrumento apresentou onze temas de ciência e tecnologia, e assim, os respondentes deveriam indicar, em uma escala de quatro pontos, o nível de informação, que em suas concepções, acreditavam deter sobre tal tema. São eles:

1) Mudanças climáticas/Efeito estufa; 2) Informática e tecnologia; 3) Poluição/Uso de recursos naturais/Biodiversidade; 4) Evolução das espécies; Origem da vida; 5) Cura de doenças/novos medicamentos; 6) Fontes de energias renováveis; 7) Animais pré-históricos, fósseis e descobertas arqueológicas; 8) Engenharia genética/organismos geneticamente modificados/transgênicos; 9) História do desenvolvimento científico; 10) Exploração do universo/Buracos negros/quedas de asteroides; e 11) Robótica e nanotecnologia.

A escala consistia das seguintes divisões: Não sei nada/quase nada sobre o assunto (1 ponto); conheço pouco/apenas por ouvir falar (2 pontos); conheço bastante sobre o assunto (3 pontos); conheço bem o assunto e procuro estar atualizado (4 pontos). No final, a soma de todas pontuações, referentes a cada um dos onze temas, caracterizou a Percepção Geral de Informação do entrevistado.

Esse índice é importante para investigar, na seção seguinte, a possível correlação entre o interesse por temas científicos e o nível de: AC (TACB-S) e competência de relacionar a Física com o tema trânsito (FAT).

De todos os temas, "Engenharia genética/organismos geneticamente modificados" foi classificado como de menor grau de informação, pois apresentou o menor somatório geral de pontos. Por outro lado, a temática "Informática e tecnologia" foi aquela que os entrevistados mais revelaram ter interesse/conhecimento, sendo o item com maior pontuação. Na sequência, apresentamos em ordem crescente os temas, do menor ao maior nível de informação: $8 ; 11 ; 10 ; 9 ; 7 ; 5 ; 1 ; 4 ; 3 ; 6 ;$ e 2 .
Considerando que a pontuação mínima de cada participante poderia ser de 11 pontos e a máxima, 44 pontos, podemos considerar, seguindo a lógica dos instrumentos anteriores, que quem obtiver pontuação mínima de $60 \%$ (26 pontos), pode ser considerado um participante minimamente informado sobre temas de ciência e tecnologia. Sendo assim, apenas 47,7\% dos participantes puderam atingir esse índice. Isso significa que mais da metade dos entrevistados tinha conhecimento deficiente ou insuficiente sobre os temas apresentados.

\subsection{Análises inferenciais}

Esta última categoria de resultados apresentará as análises de correlação entre os desempenhos dos instrumentos anteriormente exibidos. Realizamos no total seis testes de correlação, a fim de verificar a hipótese de associação entre as variáveis analisadas. São eles: 1) Correlação entre ano de conclusão do Ensino Médio e o FAT; 2) Correlação entre ano de Conclusão do Ensino Médio e o PEF; 3) Correlação entre o FAT e o eixo 1 do TACB-S; 4) Correlação entre o FAT, PEF, TACB-S e PGI; 5) Correlação entre FAT e PEF; e por fim, 6) Correlação entre PEF e TACB-S.

1) Correlação entre ano de conclusão do Ensino Médio e o FAT

O objetivo deste teste foi verificar a possibilidade de notar relação entre o desempenho no FAT de indivíduos que concluíram o Ensino Médio recentemente, em contraste com os que concluíram em um intervalo maior de tempo, conforme o Quadro 5. Dentro da área da psicologia cognitiva, estudos de retenção conceitual à longo prazo [43][44][45], buscam observar um padrão de curva de esquecimento, postulado empiricamente por Hermann Ebbinghaus no século XIX. Por isso, um teste para investigar se há uma relação significativa entre a competência de aplicar os conhecimentos de Física no trânsito e o tempo de conclusão dos estudos básicos, aparentou ser pertinente.

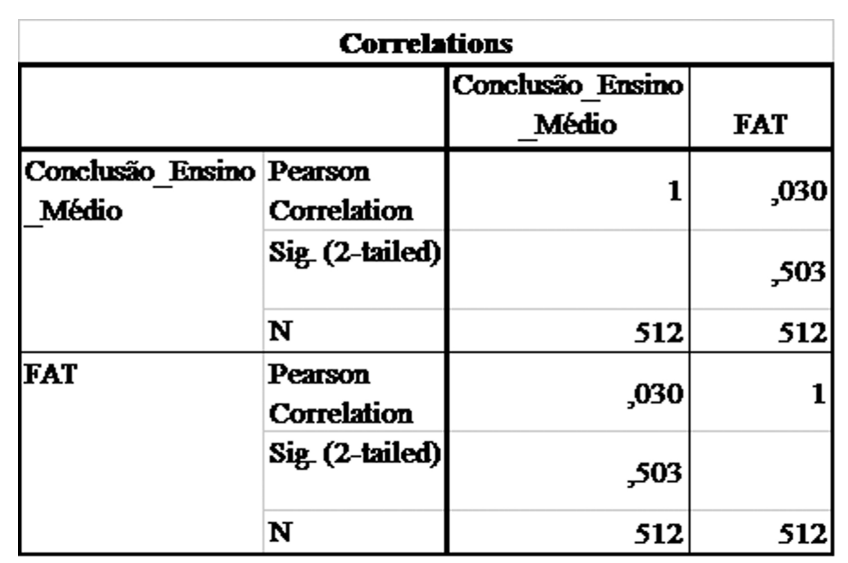

Quadro 5: Correlação entre ano de conclusão do Ensino Médio e o FAT. Fonte: autores. 
Para interpretar os quadros de resultados dos testes apresentados, necessitamos observar primeiramente, o nível de significância do resultado. Ou seja, se a correlação apresentada é estatisticamente significativa ou não. Para isso, basta verificar em "Sig. (2-tailed)" o valor apresentado. Se esse for maior que 0,05, de modo geral, significa que a correlação não é significativa. Dessa forma, pode-se concluir que, basicamente, a correlação apresentada não é relevante para esse conjunto de dados analisados. Em seguida, examinamos o "Pearson correlation" a fim de verificar a intensidade da correlação apresentada. A escala de graduação considerada segue o padrão apresentado na seção de metodologia.

Nesse contexto, podemos notar que não há correlação entre o ano de conclusão do Ensino Médio e o desempenho no FAT, ou seja, nada indica que as pessoas que terminaram os estudos mais recentemente tiveram melhores desempenhos, quando comparadas com as pessoas que concluíram o Ensino Médio em um maior intervalo de tempo. A associação não é significativa ( $\mathrm{p}$-valor $>0,05$ ) e da mesma maneira, a sua intensidade é considerada fraca.

2) Correlação entre ano de Conclusão do Ensino Médio e o PEF

Assim como no teste anterior, acreditamos ser relevante investigar a existência ou não de uma relação entre o ano de conclusão dos estudos e o perfil das aulas de Física que o egresso vivenciou, pois tal dado poderia fornecer subsídios experimentais de um panorama referente à forma com que a disciplina vem sendo abordada com o passar dos anos.

Ao analisar o Quadro 6, notamos que a correlação é estatisticamente significativa ( $\mathrm{p}$-valor $<0,05$ ), e por isso, o valor 0,243 , embora, seja considerado desprezível, de acordo com a literatura da área [40] [41], mostrou-se uma associação relevante para este conjunto de informações coletadas. Ou seja, há correlação significativa entre o ano de conclusão do Ensino Médio e o PEF. Isso significa que um ano de conclusão mais recente estava positivamente relacionado com um $\mathrm{PEF}$ de maior escore, isto é, um tipo de aula de Física com maior possibilidade de potencializar uma Aprendizagem Significativa.

3) Correlação entre o FAT e o eixo 1 do TACB-S

Julgamos relevante verificar se quem obteve um bom desempenho no eixo 1 do TACB-S, eixo com tópicos conteudistas, como nomenclaturas, significados, história da ciência, etc., também apresentaria uma alta pontuação no exercício de utilizar os conhecimentos para interpretar situações do trânsito. Essa inferência pareceu adequada, pois há um senso comum crente que aqueles que possuem conhecimentos teóricos sobre determinado assunto, possuem intrinsicamente a competência de aplicá-lo no cotidiano ou em outras situações.

No Quadro 7, notamos que a correlação é significativa ( $\mathrm{p}$-valor $<0,05)$, porém o índice é considerado correlação

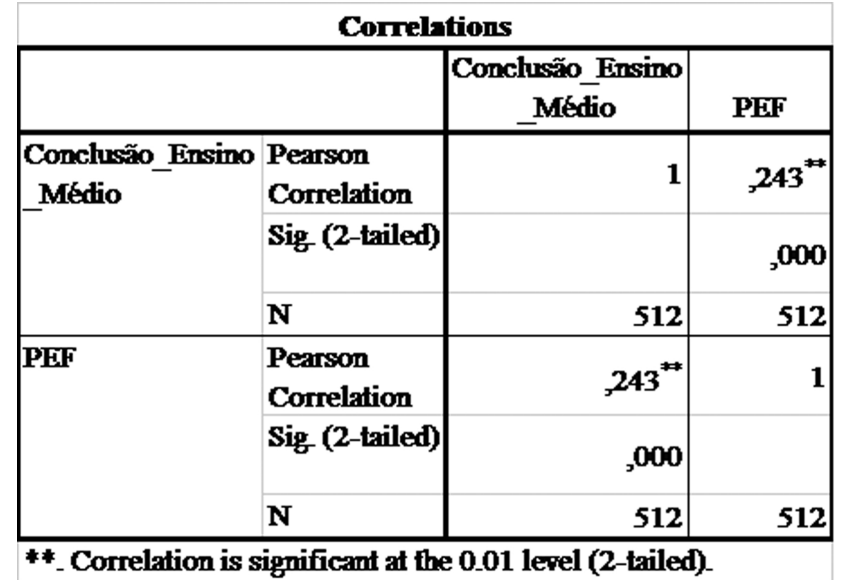

Quadro 6: Correlação entre ano de Conclusão do Ensino Médio e o PEF. Fonte: autores.

\begin{tabular}{|l|r|r|r|}
\hline \multicolumn{4}{|c|}{ Descriptive Statistics } \\
\hline & \multicolumn{1}{|c|}{ Mean } & $\begin{array}{c}\text { Std. } \\
\text { Deviation }\end{array}$ & \multicolumn{1}{c|}{$\mathrm{N}$} \\
\hline FAT & 15,97 & 3,784 & 512 \\
$\begin{array}{l}\text { Eixo_1_- } \\
\text { TACB }\end{array}$ & 18,99 & 4,845 & 512 \\
\hline
\end{tabular}

\begin{tabular}{|c|c|c|c|}
\hline \multicolumn{4}{|c|}{ Correlations } \\
\hline & & FAT & $\begin{array}{c}\text { Eixo_1_T } \\
\text { ACB }\end{array}$ \\
\hline \multirow[t]{3}{*}{ FAT } & $\begin{array}{l}\text { Pearson } \\
\text { Correlation }\end{array}$ & 1 &, $382^{* *}$ \\
\hline & Sig. (2-tailed) & &, 000 \\
\hline & $\mathrm{N}$ & 512 & 512 \\
\hline \multirow[t]{3}{*}{ Eixo_1_TACB } & $\begin{array}{l}\text { Pearson } \\
\text { Correlation }\end{array}$ &, $382^{* *}$ & 1 \\
\hline & Sig. (2-tailed) &, 000 & \\
\hline & $\mathrm{N}$ & 512 & 512 \\
\hline
\end{tabular}

**. Correlation is significant at the 0.01 level (2-tailed).

Quadro 7: Correlação entre o FAT e o eixo 1 do TACB-S. Fonte: autores

fraca. Isso vai de encontro à concepção expressa no parágrafo anterior, pois uma correlação baixa, significa que não houve um padrão de desempenho individual para os dois questionários em discussão. Explicando: quem apresentou bom escore no eixo 1 do TACB-S não necessariamente demonstrou padrão semelhante no FAT.

Verificando as informações de médias de acertos no Quadro 7, notamos que a média do eixo 1 do TACB-S (média 18,99 acertos de um total de 27 itens) foi maior que a média de acertos no FAT (média 15,97 acertos de um total de 25 itens). Essa evidência sugere que os participantes apresentaram maior desempenho em um questionário de cunho conteudista, do que em um 
questionário que instigou a aplicação dos conhecimentos em um cotidiano.

Uma correlação positiva forte poderia significar que o instrumento que mede conteúdos e o que mede aplicações e julgamentos (FAT) estariam mensurando o mesmo aspecto da AC. Como a correlação é fraca, é possível que eles estejam aferindo características diferentes da educação científica dos participantes. A distinção entre esses dois constructos será discutida abaixo.

\section{4) Correlação entre o FAT, PEF, TACB-S e PGI}

Esta quarta análise de correlação buscou investigar conexões entre todos os instrumentos utilizados. No Quadro 8, é possível inferir o grau de relação entre cada um deles.

Primeiramente, notamos que todas as correlações são significativas $(\mathrm{p}$-valor $<0,05)$. Portanto, os resultados dos quatro instrumentos estão imbricados. Porém, é possível perceber que todas elas são correlações tidas como desprezíveis $(<0,3)$ ou fracas (entre 0,3 e 0,5).

Observamos também que todas elas são positivas, ou seja, nunca o crescimento de uma variável acarretou a diminuição de outra. Isso permite defender que o interesse ou grau de informação sobre temas científicos (PGI) e uma aula de Física com condições de potencializar uma Aprendizagem Significativa, estão diretamente relacionadas com o nível geral de AC e a competência de aplicar os conhecimentos no contexto do trânsito.

O questionário FAT, em relação aos outros, demonstrou que o instrumento mais associado a ele foi o PGI $(, 320)$, seguidos do TACB-S $(, 312)$ e o PEF $(, 250)$. Ou seja, de modo muito fraco, notou-se indícios de que um maior grau

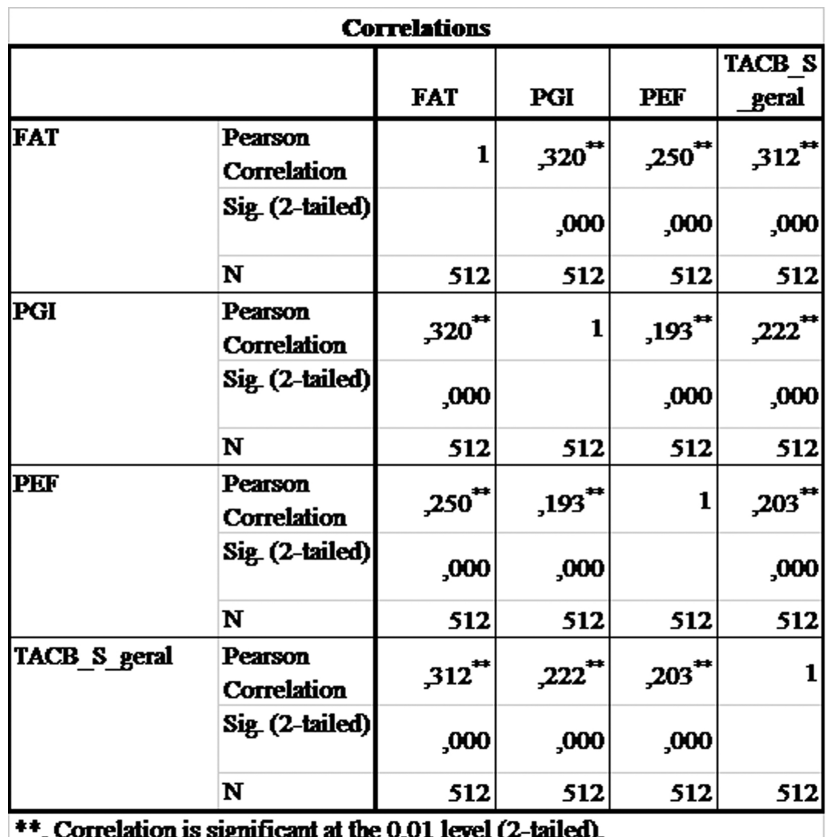

Quadro 8: Correlação entre o FAT, PEF, TACB-S e PGI. Fonte: autores. de interesse por assuntos científicos está correlacionado com uma melhor competência para julgar e interpretar os conhecimentos de Física em situações do trânsito.

Da mesma maneira, o PEF se correlacionou com maior intensidade com o FAT $(, 250)$, sendo seguidos do TACB $(, 203)$ e PGI $(0,193)$. Por fim, o TACB-S apresentou melhor ligação com o FAT $(, 312)$, e posteriormente com o PGI $(, 222)$ e o PEF $(, 203)$.

\section{5) Correlação entre FAT e PEF}

Essa categoria de inferências apresentadas nas duas últimas análises difere das anteriores, pois nessas, o software estatístico não fez uso dos dados numéricos de desempenho para efetuar suas medidas. O teste de Qui-quadrado, analisa correlações de variáveis descritivas.

Para esse particular, foram utilizadas as conclusões de desempenho sobre cada teste, o que significa que quando um participante atingia o desempenho mínimo de $60 \%$ em algum dos testes, recebia um "sim" para a pergunta referente ao teste, por exemplo: "Acertou o mínimo de $60 \%$ do FAT?"; "As aulas que ele vivenciou poderiam potencializar uma Aprendizagem Significativa?"; "O participante foi considerado alfabetizado cientificamente?".

Tendo posse dessas informações, foi possível conhecer o desempenho do público-alvo com maior profundidade.

Conforme se pode observar no Quadro 9 o teste de Qui-quadrado para os desempenhos mínimos no FAT e PEF revelou que $64,7 \%$ dos que estudaram em aulas de Física que poderiam não potencializar uma Aprendizagem Significativa, não alcançaram um desempenho satisfatório ao utilizar seus conhecimentos para julgar a coerência científica de situações de Física no trânsito. Por outro lado, 57,6\% dos que vivenciaram aulas de Física que poderiam potencializar uma aprendizagem de maior significado, atingiram o mínimo de $60 \%$ de acertos no FAT. Esta diferença possuiu um p-valor $<0,05$, sendo considerada como estatisticamente significativa.

6) Correlação entre PEF e TACB-S

\begin{tabular}{|c|c|c|c|c|c|}
\hline \multirow{2}{*}{\multicolumn{3}{|c|}{ Teste de Qui-quadrado entre FAT e PEF }} & \multicolumn{2}{|c|}{$\begin{array}{c}\text { Aulas poderiam } \\
\text { potencializar uma } \\
\text { Aprendizagem } \\
\text { Significativa? }\end{array}$} & \multirow[b]{2}{*}{ Total } \\
\hline & & & \begin{tabular}{|l|} 
Não \\
\end{tabular} & $\operatorname{sim}$ & \\
\hline \multirow{4}{*}{$\begin{array}{l}\text { Acertou o mínimo } \\
\text { de } 60 \% \text { do FAT }\end{array}$} & Não & Count & 119 & 65 & 184 \\
\hline & & $\begin{array}{l}\text { Acertou o mínimo } \\
\text { de } 60 \% \text { do FAT }\end{array}$ & $64,7 \%$ & $35,3 \%$ & $100,0 \%$ \\
\hline & $\operatorname{sim}$ & Count & 139 & 189 & 328 \\
\hline & & $\begin{array}{l}\text { Acertou o mínimo } \\
\text { de } 60 \% \text { do FAT }\end{array}$ & $42,4 \%$ & $57,6 \%$ & $100,0 \%$ \\
\hline \multirow[t]{2}{*}{ Total } & & Count & 258 & 254 & 512 \\
\hline & & $\begin{array}{l}\text { Acertou o mínimo } \\
\text { de } 60 \% \text { do FAT }\end{array}$ & $50,4 \%$ & $49,6 \%$ & $100,0 \%$ \\
\hline
\end{tabular}

Quadro 9: Correlação entre FAT e PEF. Fonte: autores. 
Assim como na inferência anterior, esta última análise tem como base o PEF. Nesse teste, todavia, buscou-se verificar a sua relação com o fato de o indivíduo ter sido considerado ou não alfabetizado cientificamente.

É possível verificar no Quadro 10 que 53,4\% dos participantes que assistiram as aulas que poderiam não potencializar uma Aprendizagem Significativa, foram considerados como não alfabetizados cientificamente. O contrário se observa com $55,6 \%$ dos que assistiram aulas que poderiam potencializar uma Aprendizagem Significativa, pois essa parcela do grupo, foi considerada alfabetizadas cientificamente. Essas observações apresentam uma perspectiva diferente aos testes anteriormente realizados, e mesmo assim, corroboram para os seus resultados. Ou seja, as correlações entre um alto PEF e os desempenhos no FAT e no TACB-S são aqui também evidenciadas.

\section{Discussões}

Após a exposição dos resultados e de uma breve análise dos dados na seção anterior, neste segmento abordaremos as principais discussões desencadeadas por esses achados.

Sobre o FAT, o instrumento instigou o respondente a utilizar os seus saberes para emitir julgamento sobre situações aplicadas ao trânsito que poderiam estar corretas ou incorretas do ponto de vista da Física. Concebemos que a aprendizagem pode acontecer em diversos espaços, não se resumindo apenas à escola. Consideramos também, que o esquecimento de certas informações, ora aprendidas, acontece naturalmente, e de acordo com Ausubel, esta ocorrência até mesmo faz parte do processo de aprendizagem [34].

Dessa maneira, se o participante externou um desempenho considerado satisfatório, pelo menos dois pontos podem ser afirmados: Inicialmente, ele pode ter aprendido tais noções na escola ou em espaços não formais ou informais de aprendizagem. E por fim, esse conhecimento esteve retido/relevante em sua estrutura cognitiva até o momento da pesquisa. Por outro lado, para os participan-

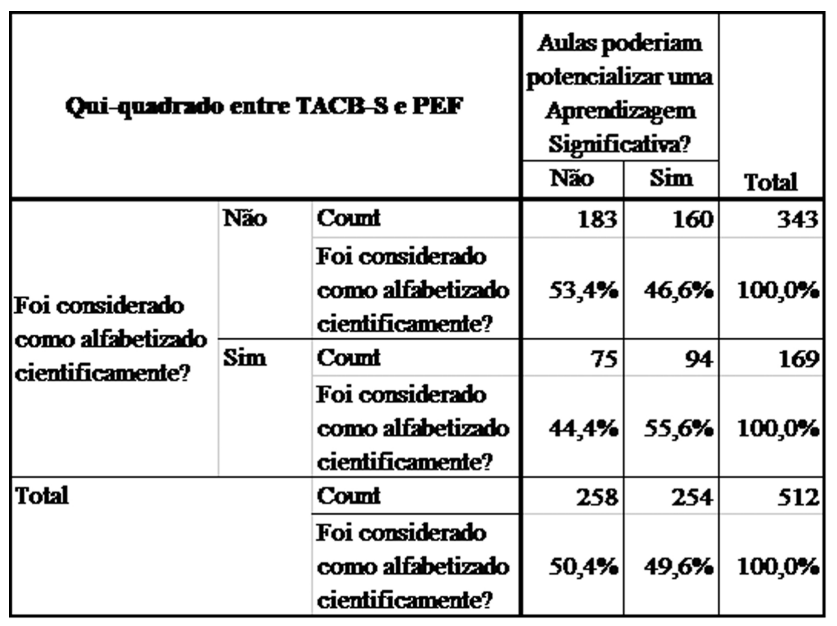

Quadro 10: Correlação entre PEF e TACB-S. Fonte: autores. tes que não obtiveram um desempenho satisfatório, esse pode significar que os mesmos não aprenderam nem na escola e nem em outros espaços informais ou não formais de ensino e aprendizagem. Ou, pode significar também que, se aprenderam em alguma ocasião, no momento da pesquisa, esse saber não o auxiliou em seus raciocínios, pois apenas 3,6\% dos 512 entrevistados atingiram um desempenho igual ou superior a $90 \%$ de acertos.

Ainda associando à Teoria da Aprendizagem Significativa com a proposição de novos contextos para aplicação de conhecimentos, julgamos que essa metodologia foi acertada pois a utilização de tal estratégia é defendida pelos seus resultados satisfatórios, também por outras produções da literatura [46] [47]. Em outras palavras, defendemos que conceitos aprendidos de modo significativo podem ter maior potencial de contribuir para o nível de AC de um indivíduo. Os resultados de correlação, conectando PEF com o TACB-S e o FAT, mesmo que de modo brando, podem atuar como uma evidência sutil para sustentar tal defesa.

Sobre o TACB-S, a conclusão de que apenas $33 \%$ da amostra pode ser considerada como alfabetizadas cientificamente infere-se que isso consiste em um índice extremamente baixo, pois os participantes eram egressos do Ensino Médio, e supostamente não se tratava da primeira vez que estavam entrando em contato com tais saberes. Entretanto, esses índices estão de acordo com os padrões verificados em pesquisas que também utilizaram tal instrumento para medir este constructo, como nos trabalhos de Laugksch e Spargo [8][25]; Camargo; Barbará; Bertoldo [29]; Nascimento-Schulze [30]; e Rivas [31].

Esses dois últimos estudos supracitados, também corroboram com nossos resultados, nos quais constatamos que o eixo 1 obteve maior índice de acertos que os demais eixos. Para as autoras, esse fato pode sinalizar uma natureza majoritariamente conteudista do Ensino das Ciências, conforme debatido na apresentação dos resultados. Sendo assim, é possível que aspectos epistemológicos (eixo 2) e que abordem discussões sobre Ciência, Tecnologia e Sociedade - CTS (eixo 3), possam estar sendo abordados de maneira mais sutil, quando comparadas às nomenclaturas e seus significados, apenas.

Sobre o quarto questionário, que buscou mensurar o grau de informação dos participantes, conforme referido, o tema de maior sinalização foi informática e tecnologia. Em segundo e terceiro lugar, foram os temas "fontes de energia renovável" e "poluição/uso de recursos naturais". Isso pode sinalizar uma maior atenção dessa geração de indivíduos para com temas de cunho ambiental.

Através das estatísticas de correlação não foi possível observar nenhum tipo de padrão (estatisticamente significativo) semelhante a uma "curva de esquecimento". Em outras palavras, não observamos uma diminuição no desempenho, conforme se aumenta o intervalo de tempo de conclusão do Ensino Médio. Isso significa que houveram maus e bons desempenhos em participantes concluintes 
de todas as faixas de tempo, conforme se pode notar no gráfico 2.

Nossa hipótese para a ausência de uma tendência a um menor desempenho no FAT e no TACB-S conforme se aumenta o intervalo de tempo de conclusão do Ensino Médio, é a de que os estudos de Pinto [43][44] e Pinto e Oliveira [45], abordavam a temática por meio de metodologia que difere da empregada pelo nosso estudo. Tais estudos mensuravam a memorização de conceitos e informações, muitas vezes desconexas entre si. Sendo assim, não buscavam observar a manipulação dos conhecimentos em aplicações de contextos diversos.

Em nossa compreensão, esse foi o diferencial do FAT, pois sua metodologia instigou os entrevistados a utilizarem seus saberes, intrínsecos ou extrínsecos para emitir julgamento sobre uma situação cotidiana. Essa aproximação com o cotidiano pode estimular a competência de resolução de problemas, conforme defende os estudos de Leite e Afonso [48] e Souza e Bastos [49].

A segunda correlação realizada, demonstrou conexão entre o ano de conclusão do Ensino Médio e o PEF. Isso significa que, a vivência em aulas que poderiam potencializar uma Aprendizagem Significativa foi identificada em participantes que concluíram seus estudos mais recentemente. Uma das possíveis explicações para esse padrão, mesmo que evidenciado de forma sutil, pode se justificar nos esforços para a busca de uma educação científica baseada no potencial das teorias de aprendizagem, metodologias ativas, inclusão de atividades experimentais, uso de tecnologias, etc., sendo esse resultado e suas implicações, um tópico que é digno de aprofundamento em produções subsequentes.

A terceira correlação apresentou um resultado inusitado. Houve uma conexão significativa, porém fraca entre o desempenho no FAT e o eixo 1 do TACB-S. Conforme referido na apresentação desses resultados, essa

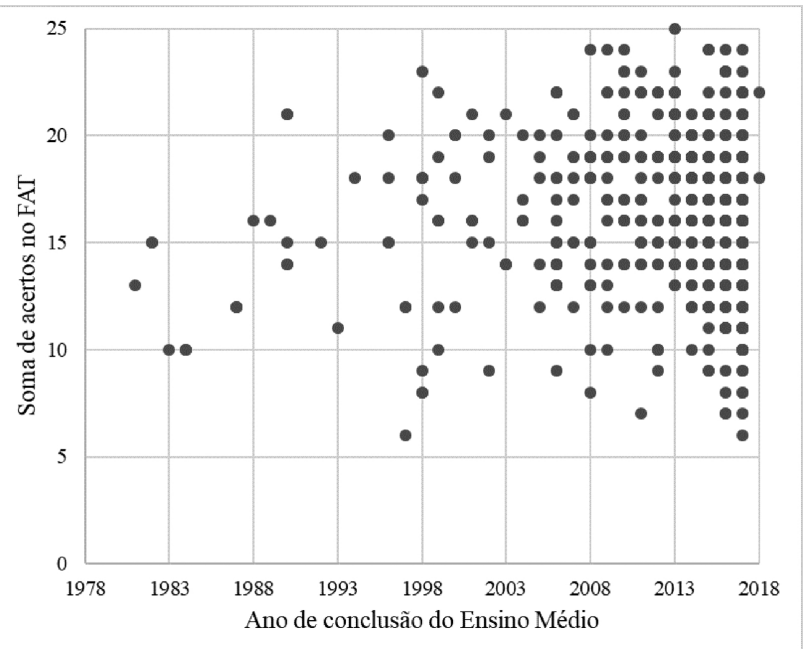

Gráfico 2: Medida de dispersão entre FAT e ano de conclusão dos estudos. Fonte: autores. diferença de desempenhos nos remete à reflexão de que tais instrumentos mediram aspectos diferentes da AC.

Notamos que a média de acertos no eixo 1 foi maior que a média de acertos no FAT. Considerando que o eixo 1 aborda itens de cunho conteudista e o FAT tem por viés a aplicação deste conhecimento, agregando a isso o fato de que a correlação entre estes dois escores foi fraca, significa que os entrevistados foram melhores no domínio conteudista do que na aplicação desses saberes em situações cotidianas. Além de tudo isso, a correlação indicou que não houve um padrão de desempenho, ou seja, quando alguém apresentou bom desempenho no eixo 1 , não necessariamente demonstrou igual desempenho no FAT.

Sobre os três eixos de Miller [6] nos quais o TACB-S está estruturado, cada um aborda um aspecto da AC. Em nosso entendimento, o FAT ocupa-se de uma característica da AC não englobada pelo instrumento de Laugksch e Spargo [8]. Denominamos essa característica de Proficiência Científica.

Por proficiência, entendemos como a habilidade, aptidão, conhecimento pleno em determinado assunto. Para Gusmão [50], no contexto do Ensino de Ciências, alguém proficiente em um determinado tópico, seria aquele que detém a capacidade de utilizar saberes científicos para elucidar de modo coerente um cenário cotidiano. Por conseguinte, legitimamos que a mensuração do eixo 1 é fundamental para a definição de AC de Miller [6], porém, é necessário verificar o quanto esses conteúdos colaboram para o entendimento crítico de situações cotidianas permeadas pela Física.

Busca-se, através da noção de Proficiência Científica [51], devido à relevância de investigar o quanto os saberes escolares colaboram para a compreensão do cotidiano, sugerir a incorporação de um quarto eixo dimensional na concepção das aptidões pertinentes para atestar uma pessoa como alfabetizada cientificamente. O eixo da Proficiência Científica se diferencia do eixo 1 (e dos demais eixos), pois este último, aborda o conhecimento básico, conceitual, e por outro lado, supõe-se proficiente quem apresenta a competência de empregar tal conhecimento para compreender cotidianos nos quais o saber em foco situa-se presente de maneira aplicada.

Para essa pesquisa, o contexto de aferição da proficiência foi o do trânsito. Porém, podem existir inúmeras situações cotidianas nas quais os saberes de Física escolar podem ser utilizados como ponto de partida para analisar a competência de aplicação desses conhecimentos. Portanto, a proficiência aqui relatada, tem validade somente dentro do contexto da Física aplicada ao trânsito, mas serve de aspiração para futuros estudos, a fim de incluir demais temáticas de aplicação cotidiana.

\section{Considerações}

Este estudo apresentou uma pesquisa que teve por objetivo mensurar o nível de AC e a capacidade de interpretar 
situações do trânsito à luz da Física. Em posse desses escores, mapeamos o perfil do Ensino de Física que os participantes vivenciaram, assim como, o grau de interesse/informação que acreditavam deter sobre temas científicos a fim de testar hipóteses de correlação entre tais fatores.

Destaca-se a necessidade de aprofundar a investigação com a intenção de inferir se as características dos participantes, como idade, sexo, nível escolar, reprovações, etc., podem ter influenciado os desempenhos dos mesmos, pois conforme foi possível observar nas análises de correlação, fatores como possuir $\mathrm{CNH}$, ou seja, deter experiências práticas, podem ter influenciado no desempenho dos testes realizados. Esse escopo será contemplado de maneira exclusiva em um manuscrito subsequente.

Todos os escores dos instrumentos utilizados apresentaram graus significativos de correlação, mesmo que de forma sutil. Na ausência de um experimento para atestar a causalidade de tais relações, concebemos que tais fatores, alinhados, podem ampliar as possibilidades de que bons resultados aconteçam na competência de articular os conhecimentos com o cotidiano. Desse modo, defendemos que conceitos físicos aprendidos de modo significativo podem ter maior potencial de contribuir para: a Alfabetização Científica; a Educação para o trânsito; e para a competência de aplicar os conhecimentos no cotidiano.

Para fins de considerações, advogamos a inclusão de um quarto eixo adicional às ideias de Miller [6] no que considera como fatores básicos para determinar o nível de alfabetização científica de um indivíduo. O eixo da Proficiência Científica exprime a necessidade de que além de deter os conhecimentos de cunho científico, a competência de utilizar os mesmos para compreender e julgar situações aplicadas ao cotidiano é um ponto relevante que deve ser considerado para o processo de mensuração da Alfabetização Científica.

\section{Material suplementar}

O seguinte material suplementar está disponível online: Anexo 1 - Questionário Física Aplicada ao Trânsito FAT.

Anexo 2 - Questionário Percepção Geral de Informação - PGI.

Anexo 3 - Questionário Perfil de Ensino de Física PEF.

Anexo 4 - Questionário Teste de Alfabetização Científica Básica Simplificado - TACB-S.

\section{Referências}

[1] D. Delizoicov e L. Lorenzetti, Ensaio Pesquisa em educação em Ciências 3, 37 (2001).

[2] C. Anelli, American Entomologist 57, 235 (2011).

[3] L.H. Sasseron e A.M.P. Carvalho, Investigações em ensino de ciências 16, 59 (2011).
[4] C. Chagas, A Física no ensino médio através do estudo de fenômenos físicos em um automóvel. Dissertação de Mestrado, Universidade Federal do Ceará, Fortaleza (2014).

[5] O. Negrini-Neto e R. Kleinubing, Dinâmica dos acidentes de trânsito: análises, reconstrução e prevenção (Millennium, Campinas, 2012), v. 4, p. 456.

[6] J.D. Miller, Daedalus 112, 29 (1983).

[7] American Association for the Advancement of Science, Science for all Americans: A project 2061 report on literacy goals in science, mathematics and technology (AAAS, Washington, 1989), v. 1, p. 256.

[8] R.C. Laugksch e P.E. Spargo, Science Education 80, 121 (1996).

[9] P. A. Vizzotto e L. F. Mackedanz, Educação em Revista 34, 1 (2018).

[10] P. A. Vizzotto e L. F. Mackedanz, Revista Prática Docente 3, 2 (2018).

[11] G.E. Deboer, Journal of Research in Science Teaching 37, 582 (2000).

[12] V.H. Noll, The Journal of Abnormal and Social Psychology 30, 145 (1935).

[13] I.C. Davis, Science Education 19, 117 (1935).

[14] A.G. Hoff, School Science and Mathematics 36, 763 (1936).

[15] P.D. Hurd, Educational leadership 16, 13 (1958).

[16] https://www.karger.com/Article/Abstract/398072.

[17] R.W. Bybee, The science teacher 62, 28 (1995).

[18] M. Mamede e E. Zimmermann, Enseñanza de las ciências, Extra, 1 (2005)

[19] R.B. Cunha, Revista Brasileira de Educação 22, 169 (2017).

[20] D. Auler e D. Delizoicov, Ensaio Pesquisa em Educação em Ciências 3, 122 (2001).

[21] J.L. Lemke, Enseñanza de las ciencias: revista de investigación y experiencias didácticas 24, 5 (2006).

[22] P. A. Vizzotto e L. F. Mackedanz, Revista Brasileira de Ensino de Física, 41, 3 (2019).

[23] http://www.foco.fae.ufmg.br/viienpec/index.php/ enpec/viienpec/paper/view/1047, acesso em fev. 2018.

[24] R.C. Laugksch, Science education 84, 71 (2000).

[25] R.C. Laugksch e P.E. Spargo, South African journal of science 95, 427 (1999).

[26] K. Murcia e R. Schibeci, International journal of science education 21, 1123 (1999).

[27] C. Chin, International Journal of Science Education 27, 1549 (2005).

[28] A. Baram-Tsabari e A. Yarden, Journal of research in science teaching 42, 403 (2005).

[29] B.V. Camargo, A. Barbará e R.B. Bertoldo, Jornada Internacional e Conferência Brasileira sobre Representações Sociais 4, 1385 (2005).

[30] C.M. Nascimento-Schulze, Psicologia: teoria e prática 8, 95 (2006)

[31] M.I.E. Rivas, Avaliação do nível de Alfabetização Científica de estudantes de biologia. Trabalho de conclusão de curso. Trabalho de Conclusão de Curso, Universidade Federal do Rio Grande do Sul, Porto Alegre (2015).

[32] D. Brossard e J. Shanahan, Science Communication 28, $47(2006)$ 
[33] Y. Özdem, P. Çavaş, B. Cavas, J. Çakiroglu e H. Ertepinar, Journal of Baltic Science Education 9, 6 (2010).

[34] D.P. Ausubel, Aquisição e retenção de conhecimentos: uma perspectiva cognitiva (Plátano, Lisboa, 2003), v. 1, p. 472.

[35] M.A. Moreira, M.C. Caballero, M.L. Rodríguez, Aprendizagem significativa: um conceito subjacente, disponível em https://www.if.ufrgs.br/ moreira/apsigsubport.pdf.

[36] M.A. Moreira, La Laguna 25, 29 (2012).

[37] L.M. Darroz, C.W. Rosa e C.M. Ghiggi, Aprendizagem Significativa em Revista 5, 70 (2015).

[38] W.L.P. Santos e E F. Mortimer, Ciência \& Educação 7, 95 (2001).

[39] L.F.S. Serrao, R. Catelli, A.L. Conrado, F. Cury e A.L.D. Lima, Cadernos de Pesquisa 46, 334 (2016).

[40] A. Field, Descobrindo a estatística usando o SPSS. (Bookman Editora, Porto Alegre, 2009), v. 2, p. 684.

[41] L. Pasquali, Psicometria: teoria dos testes na psicologia e na educação (Vozes, Petrópolis, 2017), v. 1, p. 481.

[42] C.E. Laburú, D. Silva e L.C. Vidotto, Semina: Ciências Sociais e Humanas 26, 27 (2005).

[43] A.C. Pinto, Revista Portuguesa de Pedagogia 21, 283 (1989).

[44] A.C. Pinto, Psicologia, educação e cultura 2, 215 (1998).

[45] A.C. Pinto e T. Oliveira, Revista Portuguesa de Pedagogia 25, 87 (1991).

[46] E.S. Lemos, Aprendizagem Significativa em Revista 1, 25 (2011).

[47] E.S. Lemos e M.A. Moreira, Aprendizagem Significativa em Revista 1, 15 (2011).

[48] L. Leite e A.S. Afonso, Boletim das Ciências 14, 253 (2001).

[49] C.A. Souza e F.P. Bastos, Ciência \& Educação 12, 315 (2006).

[50] F.A.F. Gusmão, Índices educacionais como preditores da proficiência em ciências: um estudo multinivel. Dissertação de Mestrado, Pontifícia Universidade Católica de São Paulo, São Paulo (2011).

[51] P. A. Vizzotto, A proficiência científica de egressos do Ensino Médio ao utilizar a Física para interpretar o cotidiano do trânsito. Tese de Doutorado, Universidade Federal do Rio Grande do Sul, Porto Alegre (2019). 